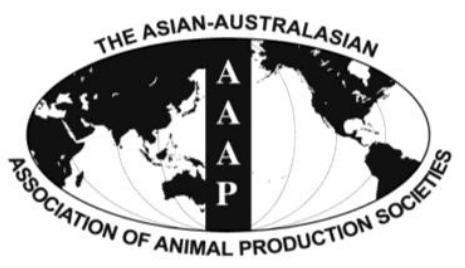

Asian-Aust. J. Anim. Sci.

Vol. 25, No. 9 : 1285 - 1293

September 2012

www.ajas.info

http://dx.doi.org/10.5713/ajas.2012.12110

\title{
The Bacillus subtilis and Lactic Acid Bacteria Probiotics Influences Intestinal Mucin Gene Expression, Histomorphology and Growth Performance in Broilers
}

\author{
H. R. Aliakbarpour, M. Chamani*, G. Rahimi ${ }^{1}$, A. A. Sadeghi and D. Qujeq ${ }^{2}$ \\ Department of Animal Science, Science and Research Branch, Islamic Azad University, \\ P.O. Box, 14515-4933, Tehran, Iran
}

\begin{abstract}
The aim of the present study was to evaluate the effect of commercial monostrain and multistrain probiotics in diets on growth performance, intestinal morphology and mucin gene (MUC2) expression in broiler chicks. Three hundred seventy-eight 1-d-old male Arian broiler chicks were allocated in 3 experimental groups for $6 \mathrm{wk}$. The birds were fed on a corn-soybean based diet and depending on the addition were labeled as follows: control-unsupplemented (C), birds supplemented with Bacillus subtilis (BS) and lactic acid bacteria (LAB) based probiotics. Each treatment had 6 replicates of 21 broilers each. Treatment effects on body weight, feed intake, feed conversion ratio and biomarkers such as intestinal goblet cell density, villus length, villus width, and mucin gene expression were determined. Total feed intake did not differ significantly between control birds and those fed a diet with probiotics ( $p>0.05$ ). However, significant differences in growth performance were found. Final body weight at $42 \mathrm{~d}$ of age was higher in birds fed a diet with probiotics compared to those fed a diet without probiotic $(\mathrm{p}<0.05)$. Inclusion of Bacillus subtilis based probiotic in the diets also significantly affected feed conversion rate $(\mathrm{FCR})$ compared with control birds $(\mathrm{p}<0.05)$. No differences in growth performance were observed in birds fed different types of probiotic supplemented diets. Inclusion of lactic acid bacteria based probiotic in the diets significantly increased goblet cell number and villus length $(\mathrm{p}<0.05)$. Furthermore, diets with Bacillus subtilis based probiotics significantly increased gene expression $(\mathrm{p}<0.05)$, with higher intestinal MUC2 mRNA in birds fed diet with probiotics compared to those fed the control diet. In BS and LAB probiotic fed chicks, higher growth performance may be related to higher expression of the MUC2 gene in goblet cells and/or morphological change of small intestinal tract. The higher synthesis of the mucin gene after probiotic administration may positively affect bacterial interactions in the intestinal digestive tract, intestinal mucosal cell proliferation and consequently efficient nutrient absorption. (Key Words: Probiotic, Bacillus subtilis, Mucin, Gene Expression, Small Intestine, Broilers)
\end{abstract}

\section{INTRODUCTION}

The chicken gastrointestinal epithelium is covered by a biological mucous layer. This layer protects intestinal absorptive surface areas against harmful microorganisms and xenobiotics, acts a lubricator and transporter between luminal contents and the brush border (Deplanck and

\footnotetext{
* Corresponding Author: Mohammad Chamani. Tel: +98-2144865100, Fax: +98-21-44865105, E-mail: fariborzchamani@ yahoo.com

${ }^{1}$ Laboratory for Molecular Genetics and Animal Biotechnology, Department of Animal Sciences, Sari Agricultural Sciences and Natural Resources University, Sari, 578-58932, Iran.

2 Department of Biochemistry and Biophysics, Faculty of Medicine, Babol University of Medical Sciences, Babol, 4717647745, Iran.

Submitted Feb. 28, 2012; Accepted Apr. 26, 2012; Revised Jun. 5, 2012
}

Gaskins, 2001; Uni et al., 2003). Therefore, this layer is the first line of the host intestinal defense and influences nutrient digestion and absorption. Mucin is the major constituent of the mucous layer (Iwashita et al., 2003) and consists of a peptide backbone containing alternating glycosylated and non-glycosylated domains (Uni et al., 2003). On the basis of amino acid sequences and structural properties, mucins are classified into three different categories which includes the gelforming/secreted mucins, the soluble mucins, and the membrane-bound mucins. Each mucin type has a characteristic structure-function relationship in a given tissue environment (Smirnov et al., 2004). Mucin2 (MUC2) is the major mucin, produced and secreted by the goblet cells in the intestinal epithelial tissue. Under normal physiological conditions, MUC2 secretion is necessary to replenish and maintain a suitable thickness of the mucous layer in the intestine, because this layer is often 
sloughed off by intestinal movement, chemical compounds and microbial derived factors (Dharmani et al., 2008; Horn et al., 2009). Different factors such as microbial colonization in the intestine can effect the production, secretion and composition of mucin (Forder et al., 2007; Azzam et al., 2011). According to previous investigations intestinal microbiota affected mucin turnover by stimulation of mucin gene expression (Smirnov et al., 2005). Mucins interact with intestine microflora because due to their high carbohydrate content and exogenous nutrients (Deplanck and Gaskins, 2001) they provide a desirable environment and nutrients for proliferation of specific microflora.

Feeding probiotics helps maintain a beneficial intestinal microflora, enhances the host's resistance to enteric pathogens such as Salmonella and Campylobacter species, and results in a healthy gastrointestinal environment with an improved intestinal function, feed conversion, weight gain and performance of birds (Dalloul et al., 2003; Vila et al., 2009; Mountzoris et al., 2010). Previous studies have shown the influence of probiotic microorganisms on intestinal morphology (Chichlowski et al., 2007). It has been reported that probiotic supplementation increased the expression of the MUC2 gene in the chicken jejunum (Smirnov et al., 2005) and rat colon (Caballero-Franco et al., 2006). Lactic acid based probiotics, which contain Lactobacilli and Bifidobacteria, are the first generation probiotic products in the market (Ohh, 2011). Lactic acid bacteria increase the acidity of the intestine, which inhibits the multiplication of harmful bacteria (Rahimi et al., 2010). There is a case for the application of microbial probiotics such as Bacillus spp. based probiotics that can be active in a wider range of environmental conditions. Although, there are to some extent valuable data regarding probiotic supplementation on broiler performance, there is little information describing the influence of different types of probiotic microorganisms on intestinal histomorphology and the quantitative pattern of mucin gene expression in broiler chickens. Thus, a better insight into how probiotics work is important to understand their role in intestinal cell proliferation and to select more efficacious strains. Therefore, the aim of the present study was to investigate the effects of Bacillus subtilis and lactic acid bacteria based probiotics on performance and mucin mRNA production in jejunal goblet cells in broiler chickens.

\section{MATERIALS AND METHODS}

\section{Birds, feeding and housing}

Three hundred and seventy eight of 1-d-old male broiler chicks were obtained from the same hatchery (Arian strain, Babol-Kenar Line Breeding Center) of the 44-wk-of-age breeding flock. On the basis of similar body weight all broiler chicks were randomly assigned into one of three treatments; control, mono and multi-bacterial based probiotic diets with 6 replicates of 126 birds in each treatment. The control birds were fed a corn-soybean based commercial diet containing no probiotic $(\mathrm{C})$. The other two groups were fed the same diet containing mono-strain (BS) and multi-bacterial (LAB) probiotics, that are commercially available as Calsporin (Calpis Co., Ltd. Tokyo Japan) and Primalac (Star Labs Inc., Clarksdale, MO, USA), respectively. The probiotics, as listed by the manufacturers, included Bacillus subtilis in the mono-strain probiotic and Lactobacillus casei, Lactobacillus acidophilus, Bifidobacterium thermophilum, and Enterococcus faecium in the multi-bacterial probiotic. The levels of 50 and 1000 $\mathrm{mg}$ of Calsporin and Primalac were supplemented per $\mathrm{kg}$ of basal diet to maintain similar cfu/g of feed, respectively.

All of dietary treatments were formulated to meet the NRC (1994) nutrient requirements for starter (1 to $21 \mathrm{~d}$ ), grower ( 22 to $35 \mathrm{~d}$ ), and finisher (36 to $42 \mathrm{~d}$ ) growth periods (Table 1). All treatment groups had free access to

Table 1. Feed composition and ingredients of experiment basal diets

\begin{tabular}{|c|c|c|c|}
\hline Component & $\begin{array}{c}\text { Starter } \\
\text { (1 to } 21 \mathrm{~d})\end{array}$ & $\begin{array}{c}\text { Grower } \\
\text { (22 to } 35 \mathrm{~d})\end{array}$ & $\begin{array}{c}\text { Finisher } \\
\text { (36 to } 42 \text { d) }\end{array}$ \\
\hline \multicolumn{4}{|l|}{ Ingredient (\%) } \\
\hline Corn & 57.1 & 62.4 & 67.6 \\
\hline Soybean meal (44\% CP) & 37.0 & 32.0 & 27.0 \\
\hline Vegetable oil & 1.25 & 1.70 & 1.58 \\
\hline DL-met & 0.29 & 0.23 & 0.22 \\
\hline L-lys $\mathrm{HCl}$ & 0.07 & 0.03 & 0.09 \\
\hline Threonine & 0.05 & 0.03 & 0.04 \\
\hline Dicalcum phosphate & 1.85 & 1.61 & 1.51 \\
\hline Limestone & 1.15 & 0.98 & 0.95 \\
\hline $\mathrm{NaCl}$ & 0.32 & 0.28 & 0.28 \\
\hline Soduim bicarbonate & 0.15 & 0.1 & 0.1 \\
\hline Cholincholoride & 0.17 & 0.14 & 0.14 \\
\hline Vitamin permix $^{1}$ & 0.3 & 0.25 & 0.25 \\
\hline Mineral permix ${ }^{2}$ & 0.3 & 0.25 & 0.25 \\
\hline \multicolumn{4}{|l|}{ Calculated analysis } \\
\hline ME (kcal/kg) & 2,907 & 3,003 & 3,050 \\
\hline $\mathrm{CP}(\%)$ & 22.13 & 20.09 & 18.21 \\
\hline $\mathrm{Ca}(\%)$ & 1.04 & 0.90 & 0.85 \\
\hline $\mathrm{AvP}(\%)$ & 0.52 & 0.45 & 0.42 \\
\hline Met $(\%)$ & 0.58 & 0.50 & 0.47 \\
\hline Lys (\%) & 1.15 & 1.00 & 0.92 \\
\hline $\operatorname{Thr}(\%)$ & 0.76 & 0.67 & 0.62 \\
\hline
\end{tabular}

${ }_{1}$ The vitamin mix provided the following (per $\mathrm{kg}$ of diet): thiamin mononitrate, $2.5 \mathrm{mg}$; nicotinic acid, $45 \mathrm{mg}$; riboflavin, $6 \mathrm{mg}$; d-calcium pantothenate, $15 \mathrm{mg}$; vitamin $\mathrm{B}_{12}$ (cobalamin), $0.025 \mathrm{mg}$; pyridoxine hydrochloride, $3 \mathrm{mg}$; d-biotin, $0.15 \mathrm{mg}$; folic acid, $1.5 \mathrm{mg}$; choline chloride, $840 \mathrm{mg}$; cholecalciferol, 4,000 IU; trans-retinyl acetate, 10,000 $\mathrm{IU}$; all-rac- $\alpha$-tocopheryl acetate, $55 \mathrm{IU}$; ethoxyquin, $1.25 \mathrm{mg}$.

2 The trace mineral mix provided the following (per $\mathrm{kg}$ of diet): manganese (manganase oxide), $120 \mathrm{mg}$; iron (ferrous sulfate), $40 \mathrm{mg}$; zinc (zinc oxide), $100 \mathrm{mg}$; copper (copper sulfat), $16 \mathrm{mg}$; iodine (calcium iodate), $1.25 \mathrm{mg}$; selenium (sodium selenate), $0.3 \mathrm{mg}$. 
feed and water. The lighting schedule and the house temperature throughout the experiment were provided according to Arian broiler breeder management guidelines (Arian, Iran). The broilers were reared on wood shavings litter and assigned to a clean floor pen $(2 \times 1 \mathrm{~m})$, with one hanging tube feeder and four nipple drinkers. For inhibition of cross contamination of probiotic between experimental pens the treatment unites were separated by plastic sheets. Mortality in each experimental unit was recorded daily throughout the experiment.

\section{Culture media and probiotic flora count}

Culturing techniques were used for the total microbial enumeration of commercial probiotics. Lactic acid bacteria in multi-bacteria probiotics were counted according to the method developed by Star Labs Inc, USA (Willis and Reid, 2008). Briefly, probiotic products were diluted in sterile saline, then Lactobacillus spp., Bifidibacterium and Enterococcus, were cultured in MRS Agar medium (Scharlau, Barcelona, Spain) with 1\% Methyl blue dye, Reinforced Clostridial Media (Quelab, Montréal, Québec. Canada) with $1.0 \mathrm{ml}$ of $0.1 \mathrm{mg} / \mathrm{ml}$ Vancomycin (Sigmaaldrich, Germany) and KF Streptococcus agar (Merck, Germany) respectively.

The mono-strain probiotic product was cultured for enumeration of Bacillus subtilis in Trypticase soy agar (Merck, Germany) after dilution in sterile saline (Leuschner and Bew, 2003). Results were expressed as $\log _{10}$ colony forming units per gram probiotic product.

\section{Performance analysis and sample collection}

Growth performances of broilers were evaluated by recording body weight gain, feed intake and feed conversion ratio during the $42 \mathrm{~d}$ experimental period. Chicken body weight was individually measured once a week. Feed intakes of birds were recorded on a per pen basis, the uneaten feed was discarded and fresh feed replaced in feeders at the end of each day. Feed conversion ratio (FCR) was calculated as the amount of feed consumed per unit of body weight and was corrected for body weight of mortality. At the end of the study, six birds from each treatment group selected (one randomly selected bird from each pen) and slaughtered.

The intestinal segments were removed and tissue samples were taken from the midpoint of the jejunum (between the point of entry of the bile duct and Meckel's diverticulum). Approximately, $2 \mathrm{~cm}$ of tissue samples were taken for histology, washed in PBS, and fixed in formalin. Samples for mRNA quantification were frozen in liquid nitrogen container, transported to the laboratory and stored at $-80^{\circ} \mathrm{C}$ until used for real time qPCR assay.

\section{Histomorphometric measurements}

The intestinal segment after flushing in PBS was fixed in $10 \%(\mathrm{v} / \mathrm{v})$ buffered formalin, dehydrated, cleared and embedded in paraffin. Serial sections were cut at $3 \mu \mathrm{m}$ by microtome (Sakura SRM 200, Tokyo, Japan) and were fixed on glass slides with three replicates, deparaffinized in xylene, rehydrated, and stained with hematoxylin and eosin. Sections were examined by light microscopy according to Burkholder et al. (2008). Fifteen villi were randomly selected on each slide. Measurements for villi length and width were taken from the tip of the villus to bottom and at the bottom of villi respectively (Awad et al., 2006). Measurements for crypt depth were taken from the base of the villus to the submucosa (Girish and Smith, 2008). Villus surface area was calculated from villus height and width at half height (Geyra et al., 2001).

Neutral and acidic mucin were assessed by staining with periodic acid-Schiff (PAS) and Alcian Blue (AB), respectively. Deparaffinized and rehydrated sections were immersed in $5 \mathrm{~g} / \mathrm{L}$ of periodic acid (Merck, Germany) for $20 \mathrm{~min}$, washed, and immersed with Schiff's reagent (Sigma Chemicals Co., St. Louis, MO, USA) for $30 \mathrm{~min}$. After washing in warm water, the slides were dehydrated and mounted. For determine of acid mucin, deparaffinized and rehydrated sections were immersed in $0.5 \mathrm{~mol} / \mathrm{L}$ acetic acid for $3 \mathrm{~min}$ and then in Alcian Blue solution $(10 \mathrm{~g} / \mathrm{L}$ in $0.5 \mathrm{~mol} / \mathrm{L}$ acetic acid $\mathrm{pH} 2.5$ ). After washing in warm water, the slides were dehydrated and mounted. Density of goblet cells were calculated according to Smirnov et al. (2004). Then number of PAS and AB positive goblet cells was measured by light microscopy.

\section{Intestinal mucin mRNA quantification}

Total RNA was extracted using Accuzol reagent (10 $\mathrm{ml} / \mathrm{g}$ of tissue) from the intestinal segment according to the manufacturer's instructions (Bioneer, Cat. No. K33090). The quantity and quality of isolated RNA were determined for each sample using both UV absorbance as well as by agarose gel electrophoresis. Reverse transcription was performed using Quantifast Revears-Transcriptase cDNA synthesis kit (QIAGEN, Cat. N0. 205311). qPCR was carried out with a specific primer pairs (Gallus gallus, XM_421035; forward: 5'-GCTGATTGTCACTCACGC CTT-3'; reverse:5'-CTCATGCAGTTCTAGCAAGATACT3') using Quanti Fast SYBER Green PCR kit (QIAGEN, Cat. No. 204052). Housekeeping $18 \mathrm{~S}$ ribosomal RNA gene (GI 7262899; forward: 5'-CGATGCTCTTAACTGAGTGT3', reverse: 5'-GAGTATGGTTGCAAAGCTGA-3') was chosen as a reference gene. Amplification of the chicken intestinal MUC2 gene was performed for 45 cycles, which consisted of an initial activation step $\left(95^{\circ} \mathrm{C}, 5 \mathrm{~min}\right)$, denaturation cycle $\left(95^{\circ} \mathrm{C}, 10 \mathrm{~s}\right)$ and combined annealing and extension $\left(60^{\circ} \mathrm{C}, 30 \mathrm{~s}\right)$. The $18 \mathrm{~S}$ reference gene was 
Table 2. Effect of probiotic supplementations on total feed intake, body weight, feed conversion ratio and mortality in broilers at $42 \mathrm{~d}$ of age

\begin{tabular}{lcccc}
\hline Component & $\mathrm{C}$ & $\mathrm{BS}$ & $\mathrm{LAB}$ & $\mathrm{p}$-value \\
\hline Body weight (g/bird) & $2,608.99 \pm 15.03^{\mathrm{b}}$ & $2,672.23 \pm 12.00^{\mathrm{a}}$ & $2,664.92 \pm 12.97^{\mathrm{a}}$ & 0.0085 \\
Feed intake (g/bird) & $4,717.41 \pm 29.56$ & $4,708.19 \pm 60.42$ & $4,764.85 \pm 23.23$ & 0.5894 \\
Feed conversion & $1.81 \pm 0.01^{\mathrm{a}}$ & $1.76 \pm 0.02^{\mathrm{b}}$ & $1.79 \pm 0.01^{\mathrm{ab}}$ & 0.0307 \\
Mortality (\%) & $7.14 \pm 3.36$ & $6.35 \pm 2.86$ & $7.94 \pm 3.42$ & 0.9517 \\
\hline
\end{tabular}

$\overline{\mathrm{a}, \mathrm{b}}$ Values are expressed as means \pm SE. Means with different superscripts within the same row differ significantly ( $\leq 0.05$ ). $\mathrm{C}=\mathrm{Control}$ group (no addition probiotic); BS = Birds supplemented with Bacillus subtilis based probiotic; LAB = Birds supplemented with lactic acid bacteria based probiotic.

amplified at 35 cycles under the same conditions in a different tube. In each PCR run, preparation of standard curve was carried out by serial dilution of pooled cDNA from samples. The relative expression ratio of MUC2 as a target gene was normalized to $18 \mathrm{~S}$ ribosomal RNA gene using $2^{-\Delta \Delta c t}$ method as previously described by Livak and Schmittgen (2001). Quantification for each treatment group was performed in triplicates.

\section{Statistical analysis}

Data were analyzed by one-way ANOVA in which the main effect was dietary treatment (control, Bacillus subtilis or lactic acid bacteria based probiotics) using the GLM procedures of SAS (SAS Institute Inc., 2003). Percentage mortality data were transformed by the arc-sine method before analysis (O'Dea et al., 2006). The statements of statistical significance were based on $\mathrm{p}<0.05$ and the variation between samples is expressed as mean \pm SE. Differences between means were examined using Duncan's multiple range test.

\section{RESULTS}

\section{Broiler performance}

Data on total feed intake, body weight gain and feed conversion ratio of broilers at $42 \mathrm{~d}$ of age using rations containing different probiotics are presented in Table 2.
Broilers feed intake did not differ between the experimental treatments and control group $(\mathrm{p}>0.05)$. Probiotic fed broilers had higher body weight compared with control chickens $(\mathrm{p}<0.05)$. Significant differences between treatments were noted in the feed conversion ratio $(p<0.05)$ during the rearing period. The effect of probiotic supplementation was shown to be favorable as birds on BS treatment had significantly lower FCR value than the control birds $(p<0.05)$, but these values did not statistically differ between the control group and birds fed a LAB diet. No differences were found between probiotic supplemented diets on total feed intake, body weight and feed conversion ratio. There were no significance $(p>0.05)$ differences between probiotic addition groups and control for percentage mortality (Table 2).

\section{Bacterial populations}

Analysis of probiotic microbial culture indicated the presence of at least $1 \times 10^{8} \mathrm{cfu} / \mathrm{g}$ Lactobacillus, Bifidobacterium, and Enterococcus, in the multi-strain based probiotic (LAB) and $1 \times 10^{10} \mathrm{cfu} / \mathrm{g}$ Bacillus subtilis in the mono-strain probiotic (BS).

\section{Small intestinal morphology}

The effects of probiotic treated diets on small intestine histomorphometric parameters are shown in Table 3 and Figure 1. In this experiment the inclusion of $\mathrm{LAB}$ probiotic

Table 3. Effect of probiotic supplementations on histomorphological parameters of intestinal jejunum section of broilers at $42 \mathrm{~d}$ of age

\begin{tabular}{lcccc}
\hline \multirow{2}{*}{ Component } & \multicolumn{3}{c}{ Experimental treatments ${ }^{1}$} & p-value \\
\cline { 2 - 5 } & $\mathrm{C}$ & $\mathrm{BS}$ & $\mathrm{LAB}$ & 0.0445 \\
Villus length $(\mu \mathrm{m})$ & $1,087.29 \pm 41.39^{\mathrm{b}}$ & $1,233.75 \pm 84.75^{\mathrm{ab}}$ & $1,379.17 \pm 73.08^{\mathrm{a}}$ & 0.9862 \\
Villus width $(\mu \mathrm{m})$ & $172.09 \pm 18.42$ & $173.30 \pm 3.42$ & $170.58 \pm 6.86$ & 0.7514 \\
Villus crypt-depth $(\mu \mathrm{m})$ & $150.77 \pm 17.67$ & $166.18 \pm 21.61$ & $148.68 \pm 12.21$ & 0.3377 \\
Villus height/crypt-depth $(\mu \mathrm{m})$ & $7.53 \pm 1.01$ & $7.72 \pm 0.86$ & $9.50 \pm 1.06$ & 0.0745 \\
Villus surface area $\left(\mathrm{mm}^{2}\right)$ & $0.291 \pm 0.022$ & $0.336 \pm 0.026$ & $0.367 \pm 0.096$ & 0.0373 \\
Goblet cell density $\mathrm{AB}^{2}$ & $1.465 \pm 0.130^{\mathrm{b}}$ & $1.473 \pm 0.046^{\mathrm{b}}$ & $1.868 \pm 0.122^{\mathrm{a}}$ & 0.3777 \\
Goblet cell density PAS & $1.218 \pm 0.113$ & $1.273 \pm 0.089$ & $1.430 \pm 0.116$ & \\
\hline
\end{tabular}

\footnotetext{
${ }^{1}$ Values are expressed as mean \pm SE. Within the same row, means with different superscripts within the same row are significantly different ( $<<0.05$ ). $\mathrm{C}=$ Control group (no addition probiotic); BS = Birds supplemented with Bacillus subtilis based probiotic; LAB = Birds supplemented with lactic acid bacteria based probiotic.

${ }^{2}$ Acid mucins were measured by staining sections with Alcian blue (AB). Values are number of goblet cells $\left(\times 10^{3}\right) / \mathrm{mm}^{2}$.

${ }^{3}$ Periodic acid-schiff stained (PAS) neutral mucins. Values are number of goblet cells $\left(\times 10^{3}\right) / \mathrm{mm}^{2}$.
} 

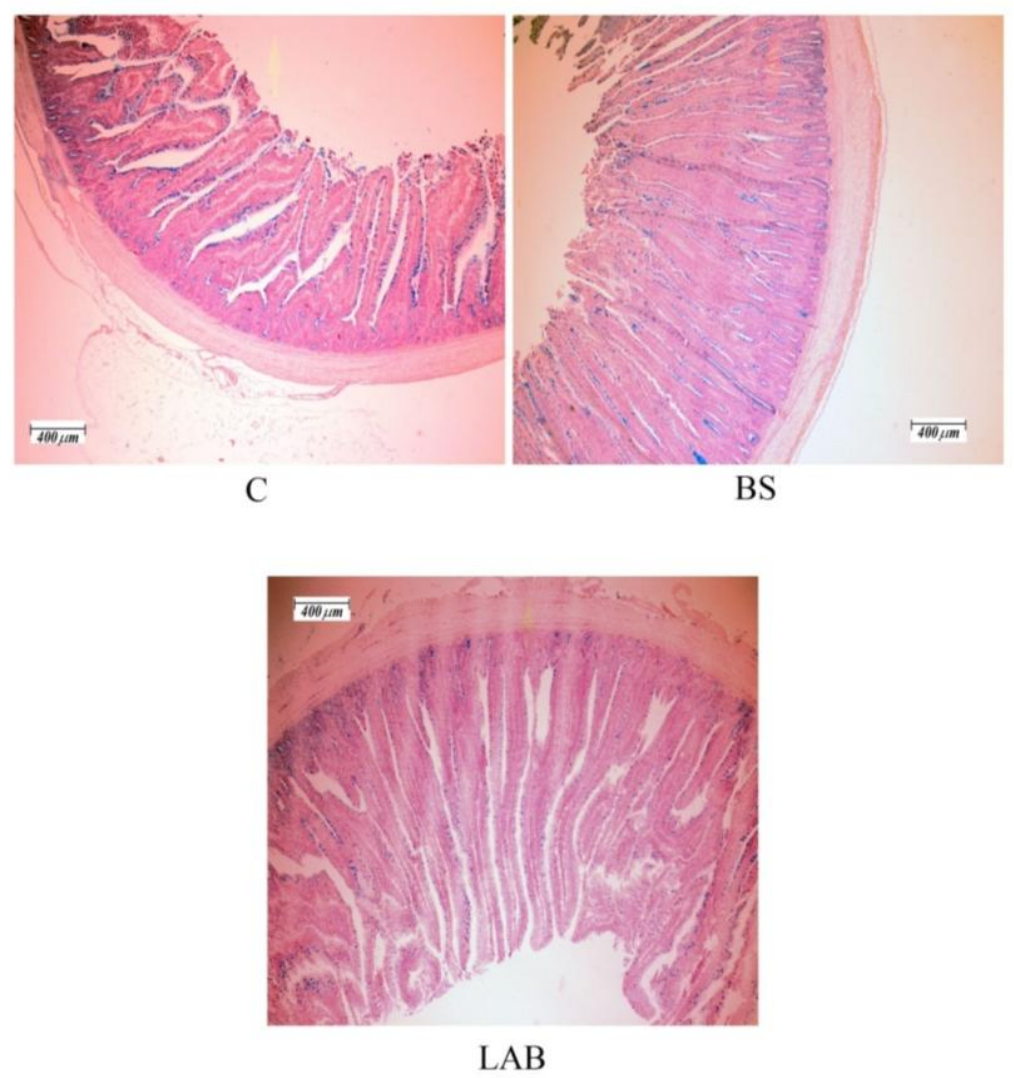

Figure 1. Photomicrograph of broiler jejunum stained with Alcian blue. Magnification $\times 40 . \mathrm{C}=$ Control group (no addition probiotic); $\mathrm{BS}=$ Birds supplemented with Bacillus subtilis based probiotic; $\mathrm{LAB}=$ Birds supplemented with lactic acid bacteria based probiotic.

in the diet increased the jejunal villus height and goblet cells density $(\mathrm{p}<0.05)$. A numerically but not a statistically significant increase in villus height was observed in the BS treated group compared with control birds. There was a tendency for an increase in villus surface area in probiotics groups but these differences were not statistically significant $(\mathrm{p}>0.05)$. The dietary treatment did not affect the other intestinal parameters such as jejunal villus-crypt depth, villus width and proportion of villus height to villus-crypt depth.

\section{Intestinal MUC2 gene expression}

The effects of probiotic treated diets on expression of the intestinal MUC2 gene are shown in Figure 2. The expression of intestinal the MUC2 gene was quantified by qPCR assay and expressed relative to expression of the $18 \mathrm{~S}$ rRNA gene. Expression of MUC2 mRNA was significantly increased in BS probiotic treated diet compared to the control group. The expression of MUC2 mRNA numerically was higher in LAB supplemented diet than the control diet, but this difference was not statistically significant $(\mathrm{p}>0.05)$. No significant differences were found in relative MUC2 gene expression between birds fed with $\mathrm{BS}$ and LAB probiotic supplemented diets.

\section{DISCUSSION}

Numerous studies have suggested that the effectiveness of a probiotics for growth stimulation of birds would be the final result of an improvement of the gastrointestinal ecosystem resulting in improved intestinal environment, integrity of the intestinal mucosal barrier, digestive and immune function of intestine and broiler health (Tellez et al., 2006; Mountzouris et al., 2010). In this sense, in addition to the growth performance and intestinal biomarker parameters, the determination of intestinal MUC2 gene expression under influence of two types of probiotic (Bacillus subtilis and lactic acid bacteria) supplementation were the main objectives of the present study.

The beneficial effect of probiotic supplementation to broiler diet in terms of increased body weight and feed conversion is documented in studies of several research groups (O'Dea et al., 2006; Timmerman et al., 2006; Onderci et al., 2008; Bansalet al., 2011). In the present study, at the 6th week of age, although there was no difference in feed intake between birds fed diet with probiotic and the control birds, birds fed probiotic treated diets had a significantly higher body weight than chicks fed a diet without probiotic $(\mathrm{p}<0.05)$. The improvement in live body weight at the end of the growth phase due to the 


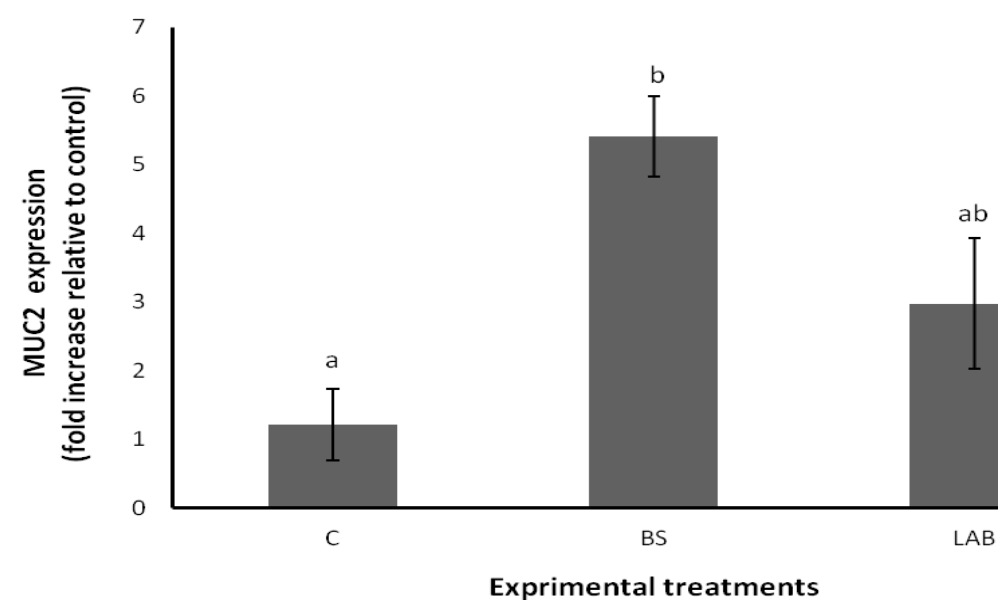

Figure 2. Result of the relative MUC2 gene expression data using real time qPCR according to $2^{-\Delta \Delta c t}$ method. Means with different superscripts differ significantly $(\mathrm{p}<0.05$ ). $\mathrm{C}=\mathrm{Control}$ group (no addition probiotic); $\mathrm{BS}=$ Birds supplemented with Bacillus subtilis based probiotic; $\mathrm{LAB}=$ Birds supplemented with lactic acid bacteria based probiotic.

supplementation of probiotic was presumed to be a result of bacterial antagonism, competition for colonization site, competition for nutrients, a reduction in toxic compounds or modulation of immune system (Applegate et al., 2010). There are conflicting reports on the effects of application of probiotic in the poultry industry because probiotic efficacy can be affected by different factors such as microbial species composition, viability, hydrophobicity of the bacterial cell surface, dosage of bacteria provided to an animal and concentration of bacteria used, frequency of application and methods of using probiotics, the combination of probiotics and synergistically acting components, bird age, overall farm hygiene, and environmental stress factors (Karimi et al., 2008; Awad et al., 2009; Flint and Garner, 2009; Mountzouris et al., 2010). In the present study, the effect of probiotic supplementation is shown to be favorable as birds on BS treatment had significantly lower FCR values than the control birds $(\mathrm{p}<0.05)$. Zhou et al. (2010) found that the use of the Bacillus based probiotic at a certain concentration in diet (cfu/g) could significantly improve the FCR in Guangxi yellow chickens $(p<0.05)$. In the present study, the LBA group (supplemented to multi bacteria based probiotic) had a lower FCR compared to control birds but these values were not statistically different $(\mathrm{p}>0.05)$, and also there was no difference in final body weight between broiler groups fed LAB and BS supplemented diets. In our experiment, a positive response in broiler growth performance in respect to final body weight and FCR as a result of inclusion of probiotic in the diet might partly be explained by intestinal histological changes and villus characteristics. It has been reported that probiotic products belonging to single or multi species of Lactobacillus, Streptococcus, Bacillus, Bifidobacterium, Enterococcus, Aspergillus, Candida, and Saccharomyces have a potential effect on modulation of intestinal microflora and pathogen inhibition (Kabir, 2009; Ohh, 2011). Most efficient probiotic microorganisms will likely be strains that are fit enough to survive in the gastrointestinal environment after application and furthermore, these microorganisms must be able to reach their targets and colonize throughout the gastrointestinal tract (Karimi et al., 2008). Intestine morphology may be mediated via alteration of intestinal microflora. It was shown that, the digestive function of the small intestine is closely related to mucosal architecture and villi structure (Liu et al., 2008). Few reports are available that have compared the effect of probiotic types on broiler intestine morphology. Some researchers have indicated that probiotic addition resulted in an increase of intestinal villus height (Chichlowski et al., 2007; Awad et al., 2009). In our experiment, probiotic addition increased the intestinal villus height. We showed that the addition of lactic acid based probiotic in the broiler diet significantly increased intestinal jejunum villus height compared to the control group $(p<0.05)$. Villus height in the BS group and the villus height to crypt-depth ratio and also villus area in BS and LAB groups were not significantly affected by inclusion of probiotics, although they were numerically higher than that of control diet. Increases of villus length could cause greater enzyme production and better digestion by increasing the effective absorptive area and improving the nutrient transport system (Awad et al., 2009). Rahimi et al. (2010) and Smirnov et al. (2005) found that addition of lactic acid based probiotics in bird's diets can induce goblet cell density and size. In our experiment, there was a tendency for an increase in goblet cells density $(p<0.05)$ when lactic acid bacteria based probiotic was added. Baurhoo et al. (2009) also reported mannanoligosaccharide supplementation in broilers diet resulted in higher Bifidibacteria concentrations in their ceca together with an increase in villi 
length and numbers of goblet cells in intestine segments.

The alteration in mucin dynamics influences gut function and health and may change nutrient absorption. Based on some previous studies, gastrointestinal microbiota can affect mucin dynamics. Smimov et al. (2005) concluded that changes in the intestinal bacterial populations by use of probiotic or antibiotic can affect processes of mucin biosynthesis and/or degradation. Mucin biosynthesis is affected by conditions or agents that affect differentiation of precursor cells into mature goblet cells and agents or conditions that uncouple the processes of glycosylation and protein synthesis, or that influence protein synthesis (Smirnov et al., 2004). Smirnov et al. (2004) found that amounts of duodenal and jejunal mucin mRNA and protein increased in response to a 72-h fast without increase in goblet cell numbers during this time. Different factors including fiber in the diet (Tanabe et al., 2005), intake of dietary threonine (Azzam et al., 2011), fasting (Thompson and Applegate, 2006), microbial colonization (Forder et al., 2007), hormones (neuropeptides) and inflammatory mediators such as cytokines and lipids can affect goblet cell activity and production and the secretion and composition of mucin (Dharmani et al., 2008). Dharmani et al. (2008) reported that colonization of bacteria in the gut can regulate mucin production by activating different signaling cascades and secretory chemical agents. Some researchers suggested that the Lactobacillus may bind to specific receptor sites on the enterocyte and stimulate the up-regulation of MUC2 (Mack et al., 1999; Mattar et al., 2002) but few reports are available that have monitored biochemical mechanisms of goblet cell sensitivity to intestine beneficial bacteria such as Bacillus spp. The use of Bacillus spp. as probiotic organisms is becoming prevalent in the poultry industry. The Bacillus species are appealing probiotic candidates because of the ability of members within this genus to form endospores that are resistant to environmental variation and processing of food (Flint and Garner, 2009), and have the ability to secret digestive enzymes (Chen et al., 2009). In the present study we quantified the intestinal MUC2 gene expression. The relative expression of MUC2 mRNA was significantly greater in the jejunum of the BS probiotic fed chicks compared with the control group $(\mathrm{p}<0.05)$. Broiler chicks that were fed mono-strain probiotic which included Bacillus subtilus had a higher mucin gene expression and also a better feed conversion rate compared to the control group, but, no significant differences were found in relative MUC2 gene expression between birds fed with BS and LAB probiotic supplemented diets.

The present study revealed that supplementation of either BS or LAB probiotics in the feed has the same potent stimulatory effects on broiler growth performance. As a consequence, the occurring of changes in intestinal morphology and/or intestinal MUC2 gene expression, may explain the improvement in growth performance observed in the present work.

\section{ACKNOWLEDGEMENTS}

The authors would like to express their deep gratitude to Dr. A. M. Karimi Torshizi from the department of poultry science, University of Tarbiat Modarres for his valuable suggestions during the course of this study. We would like to thank Dr. Z. Ansari and Mr. M. Najafy from Department of Animal Science, Sari Agricultural Science and Natural Resources University for their kind assistance during the gene expression assay. We also thank Mr. K. Yousefi from the Arian broiler line breeding center for generously providing broiler chicks, rearing and sample collection. We acknowledge Dr. M. Rezaeian from the Veterinary College of Tehran University for her kind assistance during intestinal tissue sampling.

\section{REFERENCES}

Applegate, T. J., V. Klose, T. Steiner, A. Ganner and G. Schatzmayr. 2010. Probiotics and phytogenics for poultry: Myth or reality? J. Appl. Poult. Res. 19:194-210.

Awad, W. A., K. Chareeb, S. Abdel-Raheem and J. Bohm. 2009. Effects of dietary inclusion of probiotic and symbiotic on growth performance, organ weight and intestinal histomorphology of broiler chickens. Poult Sci. 88:49-56.

Awad, W. A., J. Bohm, E. Razzazi-Fazeli, K. Ghareeb and J. Zentek. 2006. Effect of addition of a probiotic microorganism to broiler diets contaminated with deoxynivalenol on performance and histological alterations of intestinal villi of broiler chickens. Poult. Sci. 85:974-979.

Azzam, M. M. M., X. T. Zou, X. Y. Dong and P. Xie. 2011. Effect of supplemental L-threonine on mucin 2 gene expression and intestine mucosal immune and digestive enzymes activities of laying hens in environments with high temperature and humidity. Poult. Sci. 90:2251-2256.

Bansal, G. R., V. P. Singh and N. Sachan. 2011. Effect of probiotic supplementation on performance of broilers. Asian J. Anim. Sci. 5:277-284.

Baurhoo, B., P. R. Ferket and X. Zhao. 2009. Effects of diets containing different concentrations of mannanoligosaccharide or antibiotics on growth performance, intestinal development, cecal and litter microbial populations, and carcass parameters of broilers. Poult. Sci. 88:2262-2272.

Burkholder, K. M., K. L. Thompson, M. E. Einstein, T. J. Applegate and J. A. Patterson. 2008. Influence of stressors on normal intestinal microbiota, intestinal morphology and susceptibility to Salmonella enteritidis colonization in broilers. Poult. Sci. 87:1734-1741.

Caballero-Franco, C., K. Keller, C. De Simone and K. Chadee. 2006. The VSL\#3 probiotic formula induces mucin gene expression and secretion in colonic epithelial cells. Am. J. Physiol. Gastrointest. Liver Physiol. 292:315-322. 
Chen, K. L., W. L. Kho, S. H. You, R. H. Yeh, S. W. Tang and C. W. Hsieh. 2009. Effects of Bacillus subtilis var. natto and Saccharomyces cerevisiae mixed fermented feed on the enhanced growth performance of broilers. Poult. Sci. 88:309315 .

Chichlowski, M., W. J. Croom, F. W. Edens, B. W. McBride, R. Qiu, C. C. Chiang, L. R. Daniel, G. B. Havenstein and M. D. Koci. 2007. Microarchitecture and spatial relationship between bacteria and ileal, cecal and colonic epithelium in chicks fed a direct-fed microbial, Primalac, and Salinomycin. Poult. Sci. 86:1121-1132.

Dalloul, R. A., H. S. Lillehoj, T. A. Shellem and J. A. Doerr. 2003. Enhanced mucosal immunity against Eimeria acervulina in broilers fed a Lactobacillus-based probiotic. Poult. Sci. 82:6266.

Deplancke, B. and H. R. Gaskins. 2001. Microbial modulation of innate defense: Goblet cells and the intestinal mucus layer. Am. J. Clin. Nutr. 73:1131-1141.

Dharmani, P., V. Srivastava, V. Kissoon-Singh and K. Chadee. 2008. Role of Intestinal mucins in Innate host defense mechanisms against pathogens. J. Innate Immun. 8:123-135.

Flint, J. F. and M. R. Garner. 2009. Feeding beneficial bacteria: A natural solution for increasing efficiency and decreasing pathogens in animal agriculture. J. Appl. Poult. Res. 18:367378.

Forder, R. E. A., G. S. Howarth, D. R. Tivey and R. J. Hughes. 2007. Bacterial modulation of small intestinal goblet cells and mucin composition during early post-hatch development of poultry. Poult. Sci. 86:2396-2403.

Geyra, A., Z. Uni and D. Sklan. 2001. Enterocyte dynamics and mucosal development in the post-hatch chick. Poult. Sci. 80:776-782.

Girish. C. K. and T. K. Smith. 2008. Effects of feeding blends of grains naturally contaminated with Fusarium mycotoxins on small intestinal morphology of turkeys. Poult. Sci. 87:10751082.

Horn, N. L., S. S. Donkin, T. J. Applegate and O. Adeola. 2009. Intestinal mucin dynamics: response of broiler chicks and white pekin ducklings to dietary threonine. Poult. Sci. 88:1906-1914.

Iwashita, J., S. Yukita, S. Hiroko, T. Nagatomo, S. Hiroshi and A. Tatsuya. 2003. mRNA of MUC2 is stimulated by IL-4, IL-13 or TNF- $\alpha$ through a mitogen-activated protein kinase pathway in human colon cancer cells. Immunol. Cell Biol. 81:275-282.

Kabir, S. M. L. 2009. The role of probiotics in the poultry industry. Int. J. Mol. Sci. 10:3531-3546.

Karimi-Torshizi, M. A., S. Rahimi, N. Mojgani, S. Esmaeilkhanian and J. L. Grimes. 2008. Screening of indigenous strains of lactic acid bacteria for development of a probiotic for poultry. Asian-Aust. J. Anim. Sci. 21:1495-1500.

Leuschner, R. G. K. and J. Bew. 2003. Enumeration of probiotic bacilli spores in animal feed: interlaboratory study. J. AOAC Int. 86:568-575.

Liu, T., R. She, K. Wang, H. Bao, Y. Zhang, D. Luo, Y. Hu, Y. Ding, D. Wang and K. Peng. 2008. Effects of rabbit Sacculusrotundus antimicrobial peptides on the intestinal mucosal immunity in chickens. Poult. Sci. 87:250-254.

Livak, K. J. and T. D. Schmittgen. 2001. Analysis of relative gene expression data using real- time quantitative PCR and $2^{-\Delta \Delta \mathrm{ct}}$ method. Methods 25:402-408.

Mack, D. R., S. Michail, S. Wei, L. McDougall and M. A. Hollingsworth. 1999. Probiotics inhibit enteropathogenic $E$. coli adherence in vitro by inducing intestinal mucin gene expression. Am. J. Physiol. 276:941-950.

Mattar, A. F., H. Daniel, R. A. Teitelbaum, F. Drongowski, C. M. Yongy, Harmon and A. G. Coran. 2002. Probiotics up-regulate MUC-2 mucin gene expression in a Caco-2 cell-culture model. Pediatr. Surg. Int. 18:586-590.

Mountzouris, K. C., P. Tsitrsikos, I. Palamidi, A. Arvaniti, M. Mohnl. G. Schatzmayr and K. Fegeros. 2010. Effect of probiotic inclusion levels in broiler nutrition on growth performance, nutrient digestibility, plasma immunoglobulins, and cecal microflora composition. Poult. Sci. 89:58-67.

National Research Council. 1994. Nutrient requirements of poultry, 8th ed. Natl. Acad. Press. Washington, DC, USA.

O’Dea, E. E., G. M. Fasenko, G. E. Allison, D. R. Korver, G. W. Tannock and L. L. Guan. 2006. Investigating the effects of commercial probiotics on broiler chick quality and production efficiency. Poult. Sci. 85:1855-1863.

Ohh, S. J. 2011. Meta-analysis to draw the appropriate regimen of enzyme and probiotic supplementation to pigs and chicken diets. Asian-Aust. J. Anim. Sci. 24:573-586.

Onderci, M., N. Sahin, G. Cikim, A. ydyn and I. Ozercan. 2008. $\alpha-$ glucanase-producing bacterial culture improves performance and nutrient utilization and alters gut morphology of broilers fed a barley-based diet. Anim. Feed Sci. Technol. 146:87-97.

Rahimi, S., J. L. Grimes, O. Fletcher, E. Oviedo and B. W. Sheldon. 2010. Effect of a direct-fed microbial (Primalac) on structure and ultrastructure of small intestine in turkey poults. Poult. Sci. 88:491-503.

SAS Institute. 2003. SAS user's guide. Version 9.1 ed. SAS Institute Inc., Cary, NC, USA.

Smirnov, A., D. Sklan and Z. Uni. 2004. Mucin dynamics in the chick small intestine are altered by starvation. J. Nutr. 134:736-742.

Smirnov, A., R. Perez, E. Amit-Romach, D. Sklan and Z. Uni. 2005. Mucin dynamics and microbial population in chicken small intestine are changed by dietary probiotic and antibiotic growth promoter supplementation. J. Nutr. 135:187-192.

Tanabe, H., K. Sugiyama, T. Matsuda, S. Kiriyama and T. Morita. 2005. Small intestinal mucins are secreted in proportion to the settling volume in water of dietary indigestible components in rats. J. Nutr. 135:2431-2437.

Tellez, G., S. E. Higgins, A. M. Donoghue and B. M. Hargis. 2006. Digestive physiology and the role of microorganisms. J. Appl. Poult. Res. 15:136-144.

Thompson, K. L. and T. J. Applegate. 2006. Feed withdrawal alters small intestinal morphology and mucus of broilers. Poult. Sci. 85:1535-1540.

Timmerman, H. M., A. Veldman, E. van den Elsen, F. M. Rombouts and A. C. Beynen. 2006. Mortality and growth performance of broilers given drinking water supplemented with chicken-specific probiotics. Poult. Sci. 85:1383-1388.

Uni, Z., A. Smirnov and D. Sklan. 2003. Pre- and post-hatch development of goblet cells in the broiler small intestine: effect of delayed access to feed. Poult. Sci. 82:320-327. 
Vila, B., A. Fontgibell, I. Badiola, E. Esteve-Garcia, G. Jiménez, M. Willis, W. L. and L. Reid. 2008. Investigating the effects of dietary Castillo and J. Brufau. 2009. Reduction of Salmonella entericavar. Enteritidis colonization and invasion by Bacillus cereus var. toyoi inclusion in poultry feeds. Poult. Sci. 88:975979. probiotic feeding regimens on broiler chicken production and Campylobacter jejuni presence. Poult. Sci. 87:606-611.

Zhou, X., Y. Wang, Q. Gu and W. Li. 2010. Effect of dietary probiotic, Bacillus coagulans, on growth performance, chemical composition, and meat quality of Guangxi Yellow chicken. Poult. Sci. 89:588-593. 